\title{
Pure Ground Glass Nodule
}

National Cancer Institute

\section{Source}

National Cancer Institute. Pure Ground Glass Nodule. NCI Thesaurus. Code C157659.

Focal increased opacity through which normal parenchymal structures (airways and vessels) can be seen. If, on lung windows, there is a solid component of greater than or equal to $2 \mathrm{~mm}$ that is not vascular or airway, the nodule is not pure ground glass. Visibility of normal underlying interstitium is acceptable. 